\title{
Autism Spectrum Condition, Good and Bad Motives of Offending, and Sentencing
}

\author{
Jukka Varelius
}

Received: 16 August 2019 / Accepted: 31 March 2020 / Published online: 28 April 2020

(C) The Author(s) 2020

\begin{abstract}
It has been proposed that the ways in which the criminal justice system treats offenders with Autism spectrum condition (ASC) should duly account for how the condition influences the offenders' behavior. While the recommendation appears plausible, what adhering to it means in practice remains unclear. A central feature of ASC is seen to be that people with the condition have difficulties with understanding and reacting to the mental states of others in what are commonly considered as adequate ways. This article aims to clarify how the difficulties affect the moral weight to be given to the good and bad motives of offending in sentencing offenders with ASC. I start by explicating the main points of departure of the endeavor. After that I assess the moral significance of the good and bad motives of offenders with ASC in view of four cases and a comparison with how we commonly treat people who are not as able to understand and react to the mental states of others as neurotypical adults. I suggest that considerations pertaining to what has been called the primary orientation of morality provide grounds for deeming the good motives of offenders with ASC as morally significant as those of otherwise similar neurotypical
\end{abstract}

I thank Jennifer Chandler, Maria Marloth, Juha Räikkä, and two anonymous reviewers of this journal for helpful comments and the ERA-NET Neuron and the Academy of Finland (grant number 318954) for financial support.

J. Varelius $(\bowtie)$

Department of Philosophy, Contemporary History, and Political

Science, University of Turku, FIN-20014 Turku, Finland

e-mail: jukka.varelius@utu.fi offenders and the bad motives of offenders with ASC as less morally significant than those of otherwise similar neurotypical offenders. After considering three possible objections to the suggestion, I conclude by briefly elucidating its purported import.

Keywords Aggravating factor-Autism Spectrum condition · Mitigating factor - Motives of offending · Punishment $\cdot$ Sentencing

\section{Introduction}

Several authors have recently maintained that the ways in which the criminal justice system treats offenders with Autism spectrum condition (ASC) - also referred to as Autism spectrum disorder - should duly account for how ASC influences the offenders' behavior (see e.g. [1-6]). Given that an offender's ASC can affect his reasons for offending, liability, ability to defend himself in court, and response to punishment (see e.g. [3, 4, 6], the recommendation merits attention. Yet, what adhering to it means in practice remains unclear. A central feature of ASC is seen to be that people with the condition have difficulties with understanding and reacting to the mental states of others in what are commonly considered as adequate ways. ${ }^{1}$ This article aims to clarify

\footnotetext{
${ }^{1}$ It could be maintained that, insofar as persons with ASC differ from neurotypical people, the behavior of the former should not be assessed in terms of the norms and standards of the latter. The following argument is compatible with and can be interpreted to support a version of that position.
} 
how the difficulties affect the moral weight to be given to the good and bad motives of offending in sentencing offenders with ASC. ${ }^{2}$

I start by explicating the main points of departure of the endeavor. After that I assess the moral significance of the good and bad motives of offenders with ASC in view of four cases and a comparison with how we commonly treat people who are not as able to understand and react to the mental states of others as neurotypical adults. The assessment leads me to propose that considerations pertaining to what has been called the primary orientation of morality provide grounds for deeming the good motives of offenders with ASC as morally significant as those of otherwise similar neurotypical offenders and the bad motives of offenders with ASC as less morally significant than those of otherwise similar neurotypical offenders. After considering three possible objections to it, I conclude by briefly elucidating the purported import of the proposal.

\section{Starting Points}

ASC is a relatively novel, neurodevelopmental medical category. It refers to difficulties with executive function, information processing, and theory of mind, typically seen to have a strong hereditary basis. The central manifestations of the difficulties are restricted interests, repetitive behaviors, and problems with social interaction and communication. ${ }^{3}$ The symptoms generally emerge during the first two years of life and can appear in different ways and to varying degrees during a person's lifespan. People with the most challenging forms of ASC are incapable of living and functioning on their own whereas persons at the other end of the Autism spectrum can sometimes be indistinguishable from neurotypical people in everyday life. ${ }^{4}$ ASC is estimated to be found in $1 \%$ to $2 \%$ of the population in high-

\footnotetext{
${ }^{2}$ For discussion on the relationship between ASC and liability, see e.g. Grant et al. [4] and Richman and Bidshahri [7].

${ }^{3}$ While criteria for identifying ASC have been established based on the behavioral factors, the precise cognitive and affective basis of ASC is still under exploration.

${ }^{4}$ Persons at the last mentioned end of the spectrum are seen to differ from persons with Asperger's Syndrome in terms of age of onset, language development, and cognitive function. Accordingly, Asperger's Syndrome is sometimes treated as a medical category distinct from Autism. Yet, the difficulties in understanding and reacting to the mental states of others involved in "high-functioning autism" and Asperger's Syndrome are similar enough to each other for the conditions to be treated together here (see also e.g. [8], 167).
}

income countries, about the rest of the world data is lacking (see e.g. [3, 9-14]).

Difficulties with executive function, information processing, and theory of mind can assumedly all play a role in offending. Difficulties with impulse control, for instance, can lead to violence (see e.g. $[3,4,15,16]){ }^{5}$ However, the as yet nascent research on the relationship between ASC and offending has mostly focused on theory of mind. In this context, theory of mind refers to the ability to understand that others have beliefs, desires, intentions, and perspectives of their own. Resulting from complications within that area, people with ASC are seen to have difficulties in comprehending the mental states of others and, consequently, to lack ability to have appropriate affective responses to others' mental states. Grant et al. ([4], 69), for instance, write as follows:

... individuals with ASC present deficits in cognitive empathy [the capacity to understand others' feelings, including the ability to take another's perspective] and complex moral reasoning, both of which are likely due to challenges with theory of mind. By having deficits in cognitive empathy, individuals with ASC have difficulty determining another's mental state .... ${ }^{6}$

The difficulties need not necessarily mean that a person with ASC cannot care for others (see e.g. [21, 22]), but that a person with ASC is, at least, likely to express her possible care for others in ways that are seen as inadequate or misguided by the standards of conduct commonly employed.

In one view, adherence to moral rules - rules such as do not kill, do not lie, etc. - suffices for being moral (see e.g. [23]). However, although, say, robots can, in a

\footnotetext{
${ }^{5}$ Yet in view of the pertinent studies conducted so far, people with ASC are not disproportionately overrepresented in the criminal justice system (see e.g. [1, 5]). Determining the actual prevalence of ASC in the criminal justice system is, however, commonly seen to presuppose further research (see e.g. [5, 15, 17-19]).

${ }^{6}$ As suggested, the precise nature of ASC remains somewhat controversial and, accordingly, the above-described understanding of the condition is not universally accepted. For instance, it has been proposed that the problems with understanding and reacting to the mental states of others rather relate to alexithymia - a condition defined by problems in understanding and identifying one's own emotions - than to ASC [20]. Yet, as the above-described conception of ASC remains the current standard view, I here focus on it. Insofar as, say, the alternative position just mentioned is correct, what I say below applies rather to alexithymia than to ASC.
} 
sense, adhere to moral rules, few people think that robots are (full-blown) moral agents. ${ }^{7}$ Instead, (fullblown) moral agency is commonly considered to presuppose ability to understand the mental states of others and to have what are considered as adequate affective responses to those mental states. For example, consider that Alan judges that it would be morally wrong to treat Betty cruelly. A, if not the, central wrong-making characteristic of cruel behavior arguably is how such behavior feels from the viewpoint of those subjected to it. Accordingly, that Alan is able to make the moral judgment presupposes that he understands that Betty has beliefs, desires, intentions, and perspectives of her own, that there is something that it feels like to her to be treated cruelly, and that being treated in such manner is something that Betty most probably would not want to undergo. ${ }^{8}$

Of course, law and morality are not totally coextensive. Things that may be morally unproblematic - say, not carrying an identification card - can be illegal and things commonly deemed morally problematic - say, breaking a promise to a friend - can be legal. Yet, a, if not the, central function of criminal law is to protect people from what are generally considered as morally wrong actions and, not unrelatedly, to issue what are seen as morally justifiable punishments to those who commit such actions. ${ }^{9}$ The moral justifiability of punishing an offender, in its turn, plausibly depends on the degree to which she was able to account for the morally relevant aspects of her behavior. Accordingly, as proposed, the difficulties with understanding and reacting to the mental states of others people with ASC have can credibly be significant in ways that the criminal justice system should acknowledge (see also

\footnotetext{
${ }^{7}$ In a similar vein, it has been argued that psychopaths, although able to understand how others feel, are not fully morally responsible because they are unable to have appropriate affective reactions to how their behavior influences others (see e.g. [24, 25]). Needless to say, the above remarks are not meant to imply that psychopaths or people with $\mathrm{ASC}$ are robots.

${ }^{8}$ For discussion and defense of the view see e.g. Aaltola [26], Kauppinen [27], Morris [28], Persson and Savulescu [29], Schramme [30], Shoemaker [8], and also "The Moral Weight of the Motives of Offenders with ASC" section below.

${ }^{9}$ Some authors maintain that, although criminal wrongdoing can provide reason to, say, detain offenders, offenders do not deserve to be punished (see e.g. [31-33]). However, as yet at least, the view that offenders can deserve to be punished for their crimes remains more prevalent. It is also not quite clear how different the ways of treating offenders the revisionist views entail, such as detainment, would be from current criminal punishments. In any case, the considerations presented below can be of relevance for the revisionist views too.
}

e.g. $[4,34,35]$; and below). As ASC is a spectrum disorder, the extent to which offenders with ASC have such difficulties can vary. ${ }^{10}$ Yet, as the difficulties are nevertheless commonly deemed to constitute a central characteristic of ASC in general, focusing on them here is, I take it, warranted.

While offenders with the most challenging forms of ASC can lack liability, offenders with milder ASC can be liable for their offences (see e.g. [2, 4, 36, 37]). At the sentencing stage, besides acknowledging the nature of a person's offense and the range of possible punishments for it, representatives of the criminal justice system account for mitigating and aggravating factors. This includes considering such things as whether the offender was coerced, manipulated, or provoked to commit the offence in question, whether he has history of previous offending, whether the offender suffers from a mental condition that affected his conduct, and what the offender's motive was. As most jurisdictions have multiple punishment objectives - including deterrence, rehabilitation, incapacitation, and retribution, - the list of potential mitigating and aggravating factors is long (see e.g. [38-41]).

Difficulties with understanding and reacting to the mental states of others do not appear relevant in connection with all mitigating and aggravating factors. Consider, for instance, the question whether the offence a person committed caused less physical harm than similar offenses in general. Yet the difficulties seem highly relevant in connection with assessing an offender's motive. As regards to the significance of motives of offending for criminal law, Husak [40], for instance, writes as follows:

Suppose James is a greedy son who kills his elderly father for his inheritance and John is a loving son who kills his elderly father because he is wracked with pain from an incurable disease. As is well known, states do not openly allow nonvoluntary euthanasia. Thus it may be hard to appreciate how positive law could make the different motives of James and John relevant to their respective liability. Yet the failure to do so would

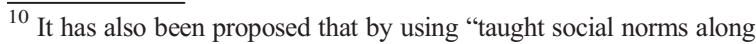
with cognitive strategies" some people with ASC can overcome (at least some of) the difficulties they have with understanding and reacting to the mental states of others ([4], 69; see also [23]; cf. [8], 169).
} 
amount to a massive injustice. Even those commentators who contend that non-voluntary euthanasia should remain illegal cannot believe that John should be treated like James, a murderer who kills from a selfish rather than a benevolent motive.

In line with the view expressed in this quotation, I now assume that in determining how it treats offenders the criminal justice system should - as criminal justice systems apparently already typically aim to do - duly account for their motives for offending. ${ }^{11}$ Here an offender's motive refers to his reasons for committing an offence. I take it that how good/bad a person's motive for behaving in a particular way is depends on the weight of the moral requirements applying to the behavior and the degree to which the person knowingly adheres to/violates them. That the unbearable suffering of a gravely ill person ought to be alleviated is a weighty moral requirement. Insofar as John's killing his father is based on John's knowingly adhering to the requirement, John's motive for the deed is good. That innocent people should not be killed (for financial gain) is a fundamental moral requirement. To the extent that James's killing his father is based on James's knowingly violating the requirement, James's motive for the deed is bad.

Besides on the factors just mentioned, the significance that good and bad motives of offending should have in sentencing can also depend on the objectives of punishment adopted and the further particulars of concrete cases. For instance, a heavily retributivist jurisdiction may assumedly weight good and bad motives of offending differently than one more focused on deterrence. And, say, James's motive could be deemed even worse if by killing his father he would inherit, not a fortune, but only a small amount of money. Consequently, I here refrain from trying to formulate a general rationale for determining the significance of good and bad motives of offending in sentencing. Instead, below I merely assume that any plausible rationale should account for the weight of the moral requirements applying

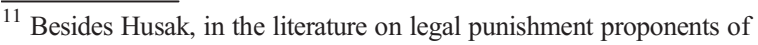
the view include Clough [42], Hessick [38], and Lincoln [43], to mention just a few examples. Even the critics of deeming motive relevant to criminal law typically qualify their position. According to Kaufman [44], for instance, "[t]he orthodox doctrine [that motive is irrelevant to criminal law] holds only that a court should not take a defendant's motive into account where the legislature (or common law) has not directed it to do so." Kaufman also allows that motive is relevant to sentencing and points out that some offences - hate crimes, for example - are defined in terms of motives.
}

to the behavior in question and the extent to which the offender knowingly adhered to/violated the requirements. Finally, while the criteria being employed in determining the moral significance of the good and bad motives of offenders likely focus on neurotypical offenders, the criteria can, I take it, be used as a starting point in determining the moral weight of the good and bad motives of offenders with ASC in the way that will be done below. With these preliminaries, I turn to assessing how ASC affects the moral weight to be given to the good and bad motives of offending in sentencing offenders with ASC.

\section{The Moral Weight of the Motives of Offenders with ASC}

Consider the following four cases:

\begin{abstract}
Neurotypical offender, mercy killing: Alan is severely ill and suffering unbearably. To alleviate his suffering, Alan's daughter Betty, a neurotypical person, kills Alan.

ASC offender, mercy killing: Chloe is severely ill and suffering unbearably. To alleviate her suffering, Chloe's son David, a person with ASC, kills Chloe.

Neurotypical offender, killing-for-money: To get Emma's money, her son Frank, a neurotypical person, kills Emma.

ASC offender, killing-for-money: To get George's money, his daughter Hannah, a person with ASC, kills George.
\end{abstract}

I now assume that Betty, David, Frank, and Hannah all met the pertinent threshold for liability. However, due to his ASC, David could not understand Chloe's mental states to the same extent as Betty understood those of Alan. David's understanding of Chloe's predicament how it felt for Chloe to suffer in the way that she did, how significant alleviating Chloe's distress was for her, etc. - was thus markedly lesser than Betty's understanding of Alan's predicament. Given that David could not appreciate the morally relevant features of Chloe's situation to as high a degree as Betty appreciated the morally relevant features of Alan's predicament, David could not knowingly adhere to the moral requirement that the unbearable suffering of a gravely ill person 
ought to be alleviated to the same extent as Betty adhered to it. For that reason, David's motive for killing Chloe meets the above-characterized criteria of a good motive to a lesser degree than Betty's motive for killing Alan. Correspondingly, because of her ASC, Hannah's motive for killing George meets the above criteria of a bad motive to a lesser degree than Frank's motive for killing Emma. ${ }^{12}$

In view of the differences just explained, it would appear to be warranted for the criminal justice system to give the good and bad motives of offenders with ASC less moral weight than those of otherwise similar neurotypical offenders. When David's motive would be given less moral weight than Betty's, the criminal justice system would apparently focus on the exact deed that David performed, that is, killed Chloe with a particular degree of good motivation. And when Hannah's motive would be given less moral weight than Frank's, the criminal justice system would apparently focus on the exact deed that Hannah performed, that is, killed George with a particular degree of bad motivation. However, conceiving of the moral weight of the motives of offenders with ASC in the just proposed way would not appear to cohere with how we commonly treat persons who are not as able to understand and to react to the mental states of others as neurotypical adults are. Consider that, say, a young child behaves kindly. Given that children acquire a theory of mind at around four years of age, ${ }^{13}$ the child is less able to appreciate the morally relevant aspects of her behavior than a neurotypical adult is. Yet the child is not responsible for lacking the mental abilities of a neurotypical adult (see also e.g. [46]) and may have behaved as skillfully as a person with her mental abilities can. Accordingly, our willingness to praise the young child need not be lesser than our willingness to praise an otherwise similar neurotypical adult. Given that the child has lesser abilities than the adult, perhaps we would praise the kindly behaving child even more than the kindly behaving adult? Although offenders with ASC are importantly different from children (see e.g. [4], 69), the case of the kindly behaving child could be seen to suggest

\footnotetext{
${ }^{12}$ I recognize that the comparisons between these cases 1-4 put forward here can sometimes be arduous to follow. Yet, as I also believe that presenting the comparisons is the most straightforward way of making the point I am trying to make, I must now beg the reader's patience.

${ }^{13}$ Yet, depending on genetic and social factors (see e.g. [45]), there can be differences between individuals in this respect.
}

grounds for questioning the view that the good and bad motives of offenders with ASC should be considered less morally weighty than those of otherwise similar neurotypical offenders. Below I both explicate those grounds in more detail and assess their plausibility.

Offenders with ASC Are Not Responsible for their Having the Condition

As the young child is not responsible for lacking the mental abilities of a neurotypical adult, David and Hannah are not responsible for their having ASC. In view of this, and given that the criminal justice system would consider Betty's good motive as a reason for treating her more leniently than it treats Frank, not counting David's good motive as morally significant as Betty's would appear to amount to unjustly punishing David for having ASC. Correspondingly, given that the criminal justice system would consider Frank's bad motive as a reason for treating her harder than Betty, deeming Hannah's bad motive less morally significant than Frank's would seem to amount to unjustly rewarding Hannah for having ASC. Hence, on the face of it, the case of the kindly behaving child would appear to suggest that the motives of offenders with ASC should be considered as morally weighty as those of corresponding neurotypical offenders.

However, our aim in praising the kindly behaving child is plausibly something like communicating to her our approval of the kind of behavior she engaged in and cultivating in her the disposition to behave in similar ways in the future. For that reason, when we praise the child, our attention arguably lies more on the compassionate disposition than on the exact deed she performed. But in connection with sentencing offenders, the focus is apparently more on punishing offenders for precisely those wrongs they committed. ${ }^{14}$ Accordingly, if Betty had accounted for the morally relevant features of Alan's predicament to the same extent into which David accounted for the morally relevant features of Chloe's situation, the criminal justice system arguably

\footnotetext{
${ }^{14}$ Punishing an offender can, of course, also involve communicating to him the censure he is seen to deserve for his crime and cultivating in him the disposition to behave in dissimilar ways in the future (see e.g. [47]). Yet, the censure communicated and the attempts to reform an offender's character engaged by the criminal justice system should arguably be strictly proportional to the seriousness of his offence. Punishment also typically involves other goals besides censure and character reform, goals such as deterrence and incapacitation.
} 
should not treat Betty as leniently as it should in the original version of the case of Alan and Betty (Neurotypical offender, mercy killing). Hence, that David would not be treated as leniently as Betty in the original version of the case of Alan and Betty need not be based on David's having ASC.

Correspondingly, if Frank had accounted for the morally relevant aspects of what he did to Emma to the same extent into which Hannah accounted for the morally relevant features of what she did to George, the criminal justice system arguably should not treat Frank as harshly as it should in the original version of the case of Emma and Frank (Neurotypical offender, killing-formoney). ${ }^{15}$ Hence, that Hannah would be treated more leniently than Frank in the original version of the case of Emma and Frank need not be based on Hannah's having ASC. Giving the motives of the offenders with ASC less moral weight than those of the otherwise similar neurotypical offenders would thus not amount to punishing or rewarding the offenders with ASC for having the condition. In view of this, even though David and Hannah are not more responsible for having ASC than the child is responsible for lacking the mental abilities of a neurotypical adult, ${ }^{16}$ the case of the kindly behaving child does not show that the motives of offenders with ASC ought to be treated like those of otherwise similar neurotypical offenders.

\section{Offenders' Motives Should Be Weighed in View of their Capacities}

That our willingness to praise the kindly behaving child need not be lesser than our willingness to praise an otherwise similar neurotypical adult might still be taken to be important here. For it suggests that a central thing in assessing the moral significance of a person's motive is the extent to which her adoption of it employs her mental capacities. In this view, assuming that David's adoption of his good motive involved his accounting for the morally relevant aspects of Chloe's predicament to

\footnotetext{
$\overline{{ }^{15} \text { In determining }}$ an offender's culpability, it is common to distinguish between purposed, knowing, reckless, and negligent wrongdoing and treat purposed the most and negligent the least culpable of these (see e.g. [48]). This supports the view that the extent to which an offender accounted for the morally relevant aspects of her deed can affect how severely she is to be treated by the criminal justice system.

${ }^{16}$ Although ASC is a hereditary condition, given that there are treatments that can help people with ASC to cope with their symptoms, an offender with ASC may sometimes be liable for failing to acquire adequate treatment for her condition.
}

the best of his ability, David's motive should be considered as morally weighty as Betty's. Correspondingly, assuming that Hannah's adoption of her bad motive involved her accounting for the morally relevant features of what she did to George to the extent that she was able, Hannah's motive should be considered as morally weighty as Frank's. ${ }^{17}$

However, consider the case of another young child. Unlike the benevolent one above, this child behaves quite malevolently. He, say, severely injures another person. When a neurotypical adult acts in the same way, she is severely blamed and faces imprisonment. Yet we commonly do not think that the malevolently behaving child should be treated as harshly as the otherwise similar neurotypical adult should. Even if the child's adoption of his bad motive fully employed his pertinent mental capacities, his malevolence is typically not considered, or at least arguably ought not to be deemed, as morally serious as that of an otherwise similar neurotypical adult (see also e.g. [49]). Similarly, even if Hannah's adoption of his bad motive fully employed her pertinent mental capacities that would not appear to warrant punishing her as harshly as Frank. Again, the case of the kindly behaving child fails to show that the motives of offenders with ASC should be considered as morally weighty as those of otherwise similar neurotypical offenders.

Morality Is Primarily about Benefiting and Avoiding to Harm People

The above considerations notwithstanding, the case of the kindly behaving child still appears relevant here. For contrasting the case with that of her malevolent agemate reminds of an asymmetry moral considerations are commonly seen to involve. Vilhauer's [50], for instance, describes the asymmetry as follows:

Justice demands that arguments for harming people be held to a higher standard than arguments for refraining from harming them or benefiting them. All philosophers should acknowledge that this asymmetry exists, though disagreement is to be expected when it comes to giving a detailed

\footnotetext{
${ }^{17}$ I now assume that both Betty and Frank fully employed their pertinent mental capacities in adopting their motives for the offences they performed.
} 
explanation of why it exists. Everyone should agree that, in one sense or another, the primary orientation of morality is to give people reasons to benefit and avoid harming other people. If this is right, then arguments for harming people oppose the orientation of morality (in at least a prima facie way), while arguments for benefiting people align with it.

As Vilhauer suggests in the above quotation, that harming other people opposes "the primary orientation of morality" does not mean that harming other people is always all in all morally unwarranted. When people violate important moral and legal restrictions, serving the primary goal of morality can assumedly involve causing those people some harm. Accordingly, as Betty, David, Frank, and Hannah all illegally killed another person, that the criminal justice system consequently causes them some harm is, I now take it, justifiable. Yet, deeming David's good motive less morally weighty than Betty's would apparently harm David more than treating his motive as morally weighty as hers. For in the former case David would assumedly be treated harder than he would were his motive considered as morally weighty as Betty's. And deeming Hannah's bad motive as morally weighty as Frank's would apparently harm Hannah more than treating her motive less morally weighty than his. For in the former case Hannah would assumedly be treated harder than she would were her motive considered less morally weighty than Frank's. Hence, "the primary orientation of morality" supports the view that the motives of offenders with ASC should have less moral weight than those of otherwise similar neurotypical offenders in Hannah's case, but deviates from it in David's case. ${ }^{18}$

As David did not account for the morally relevant features of Chloe's predicament to the degree that Betty accounted for the morally relevant features of Alan's

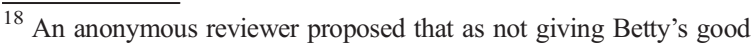
motive more moral weight than David's and not deeming Frank's bad motive of equal weight with Hannah's would result in treating the neurotypical offenders harder than they would otherwise be treated, we could here get a different conclusion just by looking at things from the perspectives of the neurotypical offenders. The proposal could be relevant to reassessing the criteria being used in determining the moral weight of the good and bad motives of Betty and Frank. Determining what kind of import it would have in the connection would presuppose weighing it with such considerations as the particular kind of punishment objectives adopted (see "Starting Points" section above). As the reassessment does not appear directly relevant to examining, as I have done above, whether the good and bad motives of offenders with ASC ought to be given less moral weight than those of neurotypical offenders are being given, I now put the task aside.
}

predicament, treating David's good motive as morally significant as Betty's would amount to treating dissimilar cases similarly. In some views at least, this would be morally problematic. Yet treating David's motive as morally significant as Betty's would apparently not harm Betty as much as treating David's motive less morally significant than Betty's would harm David. From Betty's viewpoint, treating David's motive as morally significant as hers would just mean that David would be treated as leniently as she. But, as said, giving David's motive less moral weight than Betty's would assumedly mean that David would be treated harder than he would were his motive considered as morally weighty as Betty's motive. Given that treating dissimilar cases dissimilarly would here conflict more with "the primary orientation of morality," treating the good motives of Betty and David as equally morally weighty would appear to be the preferable option, even if treating dissimilar cases similarly were considered pro tanto morally problematic. Accordingly, focusing on "the primary orientation of morality" suggests that the good motives of offenders with ASC should be deemed as morally weighty as those of otherwise similar neurotypical offenders and the bad motives of offenders with ASC as less morally weighty than those of otherwise similar neurotypical offenders. ${ }^{19}$

\section{Possible Objections}

Yet things could evidently be deemed more complicated than the above considerations suggest. Below I turn to some possible objections. ${ }^{20}$

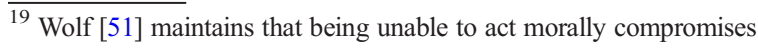
moral blameworthiness whereas being unable to act immorally is compatible with moral praiseworthiness. Yet Wolf's argument refers to persons who are kind enough to be unable to hurt a fly or so honest that they cannot tell a lie. David's case differs from such cases in that his ASC does not make him unable to behave morally wrongly.

${ }^{20}$ An anonymous reviewer proposed that the most intuitive argument for treating an offender with ASC leniently would be to consider the difficulties the offender has with appreciating the morally relevant features of his behavior as warranting lower moral expectations in his case. Therefore, the argument proceeds, the moral shortages of an offender with ASC ought to be mitigated by giving the offender's good motive possibly even more moral weight than that of an otherwise similar neurotypical offender. However, the argument would appear to lack an adequate account of what would warrant giving the ASC offender's good motive the kind of moral significance proposed. Hence, the argument should apparently be complemented with some such considerations as those related to "the primary orientation of morality" above, at least.
} 
Harm Can be Defined as Absence of Benefit and Vice Versa

When a person has a moral duty to benefit another - as, say, a parent of a young child has, - his failure to meet the duty can count as harming the other person in question. Correspondingly, when a person has a moral duty to cause some harm to another - as, say, a representative of the criminal justice system responsible for punishing an offender can assumedly have, - her failure to meet the duty may count as benefiting the other person in question. In view of this, someone might now argue that the above conception of the asymmetry of morality is incoherent. If harms can be about benefits and benefits about harms, the criticism could continue, harming and benefiting cannot be morally asymmetrical in the above-presupposed way. Hence, the conclusion of the critic could be, the argument of this article is implausible.

However, here it is important to distinguish between defining harm and benefit, on one hand, and justifying harming and benefiting, on the other. Even when benefit is defined as deprivation of harm, benefiting a person can nevertheless be seen to accord with the primary orientation of morality. Correspondingly, even when harm is defined as deprivation of benefit, harming a person can nevertheless be seen to oppose the primary orientation of morality. It is still coherent to maintain that "[j]ustice demands that arguments for harming people be held to a higher standard than arguments for refraining from harming them or benefiting them" ([50], 774). Accordingly, the conception of the asymmetry of moral considerations the argument of this article presupposes is not incoherent in the way this possible objection suggests.

The Argument Implies that all Motives for Mercy Killing Should Be Considered Equally Morally Weighty

Consider one more case, that Ida and James. The case is otherwise similar to that of Alan and Betty (Neurotypical offender, mercy killing), except that the offender, James, accounted for the morally relevant aspects of Ida's predicament to the same degree as David accounted for the morally relevant features of Chloe's situation (ASC offender, mercy killing). A critic could now maintain that the above argument entails that James's motive should be given the same moral weight as Betty's. After all, deeming James's motive less morally weighty than Betty's would appear to be as harmful to James as treating David's motive less morally weighty than Betty's would be to David. Given that this line of thinking applies to mercy killing in general, the critic could continue, the argument of this article implies that all motives for mercy killing should be considered equally morally weighty. As one mercy killer can, however, account for the morally significant aspects of her victim's predicament to a significantly lesser degree than another, the critic could conclude, the argument is implausible.

Yet, as a neurotypical adult, James had the ability to appreciate fully the morally relevant aspects of Ida's predicament. Hence, it can be justifiably maintained that James is liable for failing to account for them. But, as explained, due to his ASC, David lacked the ability to appreciate fully the morally relevant aspects of Chloe's predicament. Hence, it cannot be justifiably maintained that David is liable for failing to account for them. As the primary orientation of morality is not to be followed in abstract of the morally relevant features of the cases, James's motive can justifiably be considered less morally weighty than Betty's. So, giving the good motives of Betty and James the same moral weight would apparently be, at least, significantly less justifiable - or, say, markedly farther from a reflective equilibrium (see e.g. [52, 53]) - than giving the good motives of Betty and David the same moral weight (see also note 18 above). Hence, contrary to what this possible objection suggests, the argument of this article does not entail that the motives of all mercy killers should be considered equally morally weighty. ${ }^{21}$

\section{The Considerations Are of Marginal Interest at Best}

Although some offences may be more common among those performed by people with ASC than other offences, mercy killing or killing people for inheritance

\footnotetext{
${ }^{21}$ An anonymous reviewer proposed that this conclusion appears incompatible with giving the good motives of Betty and David the same moral weight despite the fact that weighing their motives so would amount to treating dissimilar cases similarly. However, as explained, giving the good motives of Betty and James the same moral weight would ignore that, unlike David, James can be held liable for failing fully to appreciate the morally relevant aspects of his behavior. So, giving the good motives of Betty and James the same moral weight would apparently be, at least, significantly less justifiable than giving the good motives of Betty and David the same moral weight.
} 
may not be among the most common offences of offenders with ASC. ${ }^{22}$ Accordingly, a critic could also argue that the above considerations are not relevant to sentencing offenders with ASC in general. Moreover, as proposed above, the good and bad motives of offending are not the only mitigating and aggravating factors in sentencing. Hence, the conclusion of the critic could be that the main argument of this article is of quite marginal interest at best.

However, even if cases like those of David and Hannah were rare that would apparently not make such cases morally or legally unimportant. As killing is normally severely punished and people with ASC have difficulties with social interaction that can lessen their ability to defend themselves in court (see e.g. [1, 2]), such cases would also appear to merit special attention. Moreover, the above considerations focus on comparing the extents to which offenders with ASC and otherwise similar neurotypical offenders are able to account for the morally relevant features of their actions. The comparison involves no essential reference to mercy killing or killing for inheritance. Accordingly, the considerations apply in connection with the good and bad motives of other offences besides those focused on above.

Finally, in addition to good and bad motives of offending, the considerations presented above are also relevant in the cases of other mitigating and aggravating factors that presuppose that an offender understands and is able to react to the mental states of his victim, such as in assessing whether an offender acted with especial cruelty. In the cases of aggravating factors of that kind, the considerations suggest that, to the degree that an offender with ASC was unable to understand and react to the morally relevant features of his criminal action to the same extent as a corresponding neurotypical offender, the former should be treated more leniently than the latter. In the cases of mitigating factors of that kind, the considerations suggest that an offender with ASC should be treated like an otherwise similar neurotypical offender. Hence, the argument of this article need not be of that marginal interest only.

\footnotetext{
${ }^{22}$ It has been proposed that serious offending by people with ASC relates to crimes against person, rather than against property (see e.g. [54], 856). Although discussion on the offending of people with ASC often focuses on violence and sex crime, it is not clear that such offences would be especially prevalent among offenders with ASC (see e.g. [55], 33)
}

\section{Conclusion}

In this article, I have considered how the difficulties people with ASC have with understanding and reacting to the mental states of others should figure in morally weighting the good and bad motives of offending in sentencing offenders with ASC. I proposed that considerations pertaining to what has been called the primary orientation of morality - that morality is centrally about benefiting and avoiding to harm people - suggest that the good motives of offenders with ASC should be treated like those of otherwise similar neurotypical offenders whereas the bad motives of offenders with ASC should be given less weight than those of otherwise similar neurotypical offenders. This proposition has significance in the cases of offenders relevantly similar to those discussed above, at least. I also proposed that, besides in connection with good and bad motives of offending, the argument of this article is relevant in assessing the moral weight to be given to other mitigating and aggravating sentencing factors that presuppose that an offender understands and is able to react to the mental states of others in what are commonly deemed as appropriate ways.

I did not here consider such questions as, for instance, how the criminal justice system should account for the difficulties offenders with ASC can have with executive function and information processing and to what extent offenders with ASC react to punishments in the same way as neurotypical offenders do. So, the considerations presented above amount only to a small step towards determining how the criminal justice system should treat offenders with ASC. Yet the considerations might at least inspire some more discussion on a topic that apparently deserves more attention than it has received so far.

Funding Information Open access funding provided by University of Turku (UTU) including Turku University Central Hospital.

Open Access This article is licensed under a Creative Commons Attribution 4.0 International License, which permits use, sharing, adaptation, distribution and reproduction in any medium or format, as long as you give appropriate credit to the original author(s) and the source, provide a link to the Creative Commons licence, and indicate if changes were made. The images or other third party material in this article are included in the article's Creative Commons licence, unless indicated otherwise in a credit line to the material. If material is not included in the article's Creative Commons licence and your intended use is not permitted by statutory regulation or exceeds the permitted use, you will need to obtain 
permission directly from the copyright holder. To view a copy of this licence, visit http://creativecommons.org/licenses/by/4.0/.

\section{References}

1. Allely, Clare S., and Penny Cooper. 2017. Jurors' and judges' evaluation of defendants with autism and the impact on sentencing: A systematic preferred reporting items for systematic reviews and meta-analyses (PRISMA) review of autism spectrum condition in the courtroom. Journal of Law and Medicine 25 (1): 105-123.

2. Cea, Christine N. 2014. Autism and the criminal defendant. St. John's Law Review 88: 495-529.

3. Freckelton, Ian, and David List. 2009. Asperger's disorder, criminal responsibility and criminal culpability. Psychiatry, Psychology and Law 16 (1): 16-40.

4. Grant, Tessa, Rosaria Furlano, Layla Hall, and Elizabeth Kelley. 2018. Criminal responsibility in autism spectrum condition: A critical review examining empathy and moral reasoning. Canadian Psychology 59 (1): 65-75.

5. King, Claire, and Glynis H. Murphy. 2014. A systematic review of people with autism Spectrum disorder and the criminal justice system. Journal of Autism and Developmental Disorders 44: 2717-2733.

6. Wauhop, Brian. 2009. Mindblindness: Three nations approach the special case of the criminally accused individual with Asperger's syndrome. Penn State International Law Review 27 (3): 959-991.

7. Richman, Kenneth A., and Raya Bidshahri. 2018. Autism, theory of mind, and the reactive attitudes. Bioethics 32: 4349.

8. Shoemaker, David. 2015. Responsibility from the margins. Oxford: Oxford University Press.

9. Adams, Marcus P. 2013. Explaining the theory of mind deficit in autism. Philosophical Studies 163: 233-249.

10. Elsabbagh, Mayada, and al. 2012. Global prevalence of autism and other pervasive developmental disorders. Autism Research 5 (3): 160-179.

11. Hens, Kristien, Ingrid Robeyns, and Katrien Schaubroeck. 2019. The ethics of autism. Philosophy Compass. https://doi. org/10.1111/phc3.12559.

12. National Institute of Mental Health (2018) Autism spectrum condition. https://www.nimh.nih.gov/health/topics/autismspectrum-disorders-ASC/index.shtml (Accessed 8 April 2019).

13. Rajendran, Gnanathusharan, and Peter Mitchell. 2007. Cognitive theories of autism. Developmental Review 27: 224-260.

14. Stout, Nathan. 2017. Emotional awareness and responsible agency. Review of Philosophy and Psychology 10: 337-362. https://doi.org/10.1007/s13164-017-0368-x.

15. Im, David S. 2016. Template to perpetrate: An update on violence in autism spectrum condition. Harvard Review of Psychiatry 24 (1): 14-35.

16. Richman, Kenneth A. 2018. Autism and moral responsibility: Executive function, reasons responsiveness, and reasons blockage. Neuroethics 11: 23-33.
17. Browning, Ann, and Laura Caulfield. 2011. The prevalence and treatment of people with Asperger's syndrome in the criminal justice system. Criminology and Criminal Justice 11 (2): 165-180.

18. Fazio, Rachel L., Christina A. Pietz, and Robert L. Denney. 2012. An estimate of the prevalence of autism-Spectrum disorders in an incarcerated population. Open Access Journal of Forensic Psychology 4: 61-80.

19. Frizzell, William, Howard Lindsay, Henry Cameron Norris, and Joseph Chien. 2019. Homicidal ideation and individuals on the autism Spectrum. Journal of Forensic Sciences. https://doi.org/10.1111/1556-4029.14002.

20. Brewer, Rebecca \& Jennifer Murphy (2016) People with Autism can Read Emotions, Feel Empathy. https://www. spectrumnews.org/opinion/viewpoint/people-with-autismcan-read-emotions-feel-empathy/ (Accessed 9 Aug 2019).

21. Krahn, Timothy, and Andrew Fenton. 2009. Autism, empathy and questions of moral agency. Journal for the Theory of Social Behaviour 39 (2): 146-166.

22. Smith, Adam. 2009. The empathy imbalance hypothesis of autism: A theoretical approach to cognitive and emotional empathy in autistic development. The Psychological Record 59 (2): 273-294.

23. Kennett, Jeannette. 2002. Autism, empathy and moral agency. The Philosophical Quarterly 52 (208): 340-357.

24. Haji, Ishtiyaque. 2010. Psychopathy, ethical perception, and moral culpability. Neuroethics 3: 135-150.

25. Levy, Neil. 2014. Psychopaths and blame: The argument from content. Philosophical Psychology 7 (3): 351-367.

26. Aaltola, Elisa. 2014. Affective empathy as Core moral agency: Psychopathy, autism and reason revisited. Philosophical Explorations 17 (1): 76-92.

27. Kauppinen, Antti. 2017. Empathy and moral judgment. In The Routledge handbook of philosophy of empathy, ed. Heidi Maibom, 215-226. New York: Routledge.

28. Morris, Stephen. 2019. Empathy on trial: A response to its critics. Philosophical Psychology 32 (4): 508-531.

29. Persson, Ingmar, and Julian Savulescu. 2018. The moral importance of reflective empathy. Neuroethics 11: 183-193.

30. Schramme, Thomas (2018) The Role of Empathy in an Agential Account of Morality: Lessons from Autism and Psychopathy. In Forms of Fellow Feeling: Empathy, Sympathy, Concern and Moral Agency. Neil Roughley \& Thomas Schramme, eds. Cambridge University Press: 307326.

31. Caruso, Gregg D. 2018. Justice without Retribution: An Epistemic Argument against Retributive Criminal Punishment. Neuroethics. https://doi.org/10.1007/s12152018-9357-8.

32. Pereboom, Derk. 2014. Free will, agency, and meaning in life. New York: Oxford University Press.

33. Waller, Bruce N. 2017. Beyond moral responsibility to a system that works. Neuroethics: 1-8. https://doi.org/10.1007 /s12152-017-9351-6.

34. McChesney, Dylon, and Mathieu Doucet. 2019. Culpable ignorance and mental disorders. Journal of Ethics and Social Philosophy 14 (3): 227-248.

35. Stout, Nathan. 2016. Conversation, responsibility, and autism spectrum condition. Philosophical Psychology 29 (7): $1-14$. 
36. Schwartz-Watts, Donna M. 2005. Asperger's Disorder and Murder. The Journal of the American Academy of Psychiatry and the Law 33: 390-393.

37. Westphal, Alexander R.N., and Rachel Loftin. 2017. Autism Spectrum condition and criminal defense. Psychiatric Annals 47 (12): 584-587.

38. Hessick, Carissa Byrne. 2006. Motive's role in criminal punishment. California Law Review 80: 89-150.

39. Hessick, Carissa Byrne, and Douglas A. Berman. 2016. Towards a theory of mitigation. Boston University Law Review 96: 161-218.

40. Husak, Douglas. 2012. "Broad" culpability and the retributivist dream. Ohio State Journal of Criminal Law 9: 449-485.

41. Roberts, Julian V. 2014. Mitigation and aggravation at sentencing. In Encyclopedia of criminology and criminal justice, ed. Gerben Bruinsma and David Weisburd, 3103-3112. New York: Springer.

42. Clough, Amanda. 2015. Mercy killing: Three's a crowd. The Journal of Criminal Law 79 (5): 358-372.

43. Lincoln, Lindsay. 2017. How the legalization of assisted suicide should inform a more principled and ethical treatment of mercy killings. The Georgetown Journal of Legal Ethics 30: 873-891.

44. Kaufman, Whitley R.P. 2003. Motive, intention, and morality in the criminal law. Criminal Justice Review 28 (2): $317-$ 335.

45. Wright, Barlow C., and Janina Mahfoud. 2012. A childCentred exploration of the relevance of family and friends to theory of mind development. Scandinavian Journal of Psychology 53: 32-40.

46. Feldman, Fred \& Skow, Brad (2016) Desert. In The Stanford Encyclopedia of Philosophy (Winter 2016 Edition), Edward N. Zalta ed., https://plato.stanford.edu/archives/win2016 /entries/desert/ (Accessed 6 Feb 2019).
47. Lee, Ambrose. 2017. Defending a communicative theory of punishment: The relationship between hard treatment and amends. Oxford Journal of Legal Studies 37 (1): 217-237.

48. Brink, David O. 2019. The nature and significance of culpability. Criminal Law and Philosophy 13: 347-373.

49. Brandenburg, Daphne. 2019. Inadequate agency and appropriate anger. Ethical Theory and Moral Practice 22: 169185. https://doi.org/10.1007/s10677-019-09982-w.

50. Vilhauer, Benjamin. 2015. Free will and the asymmetrical justifiability of holding morally responsible. The Philosophical Quarterly 65 (261): 772-789.

51. Wolf, Susan. 1980. Asymmetrical freedom. Journal of Philosophy 77: 151-166.

52. Cath, Yuri (2016) Reflective Equilibrium. In The Oxford Handbook of Philosophical Methodology, Herman Cappelen, Tamar Szabó Gendler, and John Hawthorne (eds.). New York: Oxford University Press: 213-230.

53. Weston, Mudge Ellis, and Justin McBrayer. 2019. A phenomenal defense of reflective equilibrium. Journal of Philosophical Research 44: 1-12.

54. Helverschou, Sissel Berge, and al. 2015. Offending profiles of individuals with autism Spectrum disorder: A study of all individuals with autism spectrum condition examined by the forensic psychiatric Service in Norway between 2000 and 2010. Autism 19 (7): 850-858.

55. Søndenaa, Erik, and al. 2014. Violence and sexual offending behavior in people with autism Spectrum disorder who have undergone a psychiatric forensic examination. Psychological Reports: Disability \& Trauma 115 (1): 32-43.

Publisher's Note Springer Nature remains neutral with regard to jurisdictional claims in published maps and institutional affiliations. 